\title{
Conceptual Foundations of Management of Infrastructure of Support for Small Entrepreneurship
}

\author{
Lyudmila G. Rudenko ${ }^{1}$, Natalia A. Zaytseva ${ }^{2}$, Elena A. Dzhandzhugazova ${ }^{2}$, Maria V. Petrovskaya ${ }^{3} \&$ Vera N. \\ Larionchikova $^{3}$ \\ ${ }^{1}$ S.Y. Witte Moscow University, Moscow, Russia \\ ${ }^{2}$ Plekhanov Russian University of Economics, Moscow, Russia \\ ${ }^{3}$ Russian University of Friendship of Peoples, Moscow, Russia \\ Correspondence: Lyudmila G. Rudenko, S.Y. Witte Moscow University, 12, 2nd Kozhukhovskiy St., Moscow, \\ Russia. Tel: 7-916-792-9975. E-mail: mila.k07@mail.ru
}

Received: April 23, 2015 Accepted: May 29, 2015 Online Published: July 15, 2015

doi:10.5539/ass.v11n20p220 URL: http://dx.doi.org/10.5539/ass.v11n20p220

\begin{abstract}
The article views the issues of development of conceptual frameworks of management of infrastructure of small entrepreneurship. As a result of the conducted research, the subject and object of management, as well as the forms of management functions of managerial influence are clarified; the proprietary vision of the principles of management of infrastructure of support for small entrepreneurship is given. The article also describes approaches to description of measures for support for small and medium enterprises, evaluation of effectiveness of realization of the concept, and direction of its further development. Special attention is paid to perfecting the legal base, regulating cash operations by subjects of SME, provision of access by subjects of SME to state and municipal purchases and investment resources for subjects of SME, and development of the system of micro-financing. The authors substantiate that it is necessary to distinguish two notions: "forms of management" and "methods of management". Methods of management are viewed in the article as an important legal means which is a totality of means and methods used by state authorities and their official bodies within limits, set by the law, in order to perform management and administrative influence as to certain persons and objects. At that, form of management is certain external manifestation of managerial actions (management), performed by state authorities (of federal and regional level) and by local authorities. The authors substantiate that general functions of managing socio-economic systems have remained unchanged over several recent years. However, the number and content of functions of the system of management of infrastructure of support for small entrepreneurship will differ a little, as, according to its content, it is referred to the level of socio-economic management.
\end{abstract}

Keywords: small business, infrastructure support, conceptual foundations of management, management principles, forms and methods of management, functions of management, effectiveness of management

\section{Introduction}

Development of small entrepreneurship should be viewed in aggregate and in the system with development of infrastructural support for small entrepreneurship. Systemacity of such progressive development supposes certain entity with features that are not peculiar for its separate elements. Only in aggregate, the mechanism of management of this system can reach its maximal effectiveness. The form of manifestation of this system could be the development of conceptual foundations of management of infrastructural support for small entrepreneurship.

Methodological basis for this research are works of the Russian economists and practitioners in the sphere of formation of entrepreneurial activities, development of small entrepreneurship, and infrastructure: Blinov A. O., Zhiltsov E. N., Busygin A. V., Erokhina L. I., Egorov E. N., Kazakov V. N., Kachurina M. M., Kruglova N. Y., Magomedov S. M., Morozov V. Y., Osipov Y. M., Platonova N. A., Sulpovar L. B. and others, as well as works of foreign scientists and specialists: P. Drucker, M. Weber, I. Schumpeter, V. Zombft, and others (Miller \& Bromiley, 2001; Nonano et al., 2005; Fayol, 1992).

In our opinion, modern literature pays not enough attention to conceptual foundations of management of infrastructure of support for small enterprises, which lead to creation of this article. 
Infrastructural support for small entrepreneurship is dynamically developing with state's support. In his message to the Federal Assembly dated December 4, 2014, the President of Russia emphasized the necessity for support for small and medium enterprises through creation of industrial parks in subjects of the RF (beginning from 2015, there starts a program of compensation for expenses of the subjects of the Federation for creation of industrial parks), expansion of access of SME to purchases of state companies, and determination of annual volume of purchases, elimination of discrimination of private sector in social sphere, and provision of equal access for private sector for financial resources. Also, the President spoke of the necessity for elimination of excessive control, "to refuse from the very principle of total and endless control" if "enterprise has acquired reliable reputation and haven't had any complaints during 3 years, there should be no planned examinations within state and municipal control over the following 3 years", and of fixing existing tax conditions over the following 4 years and not changing their control holidays. The President pointed out the necessity for business conversation with entrepreneurs: "It is important that representatives of business, researchers, and developers tell which barriers to take away and what support they need".

The forecast of socio-economic development of the Russian Federation for 2014 and for planned period of 2015 and 2016, the Ministry for Economic Development offered measures for support for small and medium entrepreneurship (Forecast of socio-economic development of the Russian Federation for 2014):

- Improvement of legal regulation in the sphere of accounting by subjects of SME;

- Improvement of legal system for alienation of state and municipal property, purchased by subjects of SME and the simplification of access for small enterprises as to purchase and rent of property. For this purpose, there is active popularization and development of Internet-portal www.torgi.gov.ru, aimed for posting information about auction as to state and municipal property and limited resources;

- In the sphere of statistics: improvement of methodology of selected statistical observations for activity of the SME subjects;

- Improvement of labor law which regulates relations in the SME sector;

- $\quad$ Improvement of regulatory law base of the Central Bank of Russia which regulates the implementation of cash operations by SME subjects;

- Provision of access for SME subjects to state and municipal purchases and infrastructural monopolies' purchases;

- Improving the access to financial and investment resources for SME subjects and development of micro-financing system;

- Development of mechanisms and principles of outsourcing the works (services) of companies with state share, which confirmed the programs of innovational development;

- $\quad$ Further improvement of special tax regimes for SME.

A huge attention in new forecast of socio-economic development of the RF is paid to development of competition. In the fulfillment of the order of the Government of the Russian Federation, dated June 14, 2012, there was developed the road map "Development of competition and improvement of antimonopoly policy" which includes systemic measures for development of competition in top-priority spheres for 2013-2015.

\section{Modern Approaches to Description of Functions of the System of Management of Infrastructure of Support for Small Entrepreneurship}

While creating the model of conception of management of infrastructure of support for small entrepreneurship, it is necessary to realize that there are certain differences in management in commercial organization and management at macro-level. Management at the level of the state has its peculiarity which is manifested in powerful regulating influence on the object of management (society, citizens, organization). Y. N. Starilov defines the meaning of state management as regulatory, target-oriented, organizing, executive, and regulating activities of the system of state executive power bodies which perform the functions of state management in the basis and in compliance with laws in various spheres of economic, administrative and political, and socio-cultural activities and spheres (Rossinskiy \& Starilov, 2009).

The process of management is impossible without management system which can be viewed as a certain mechanism, triggered into action by certain tolls of influence for the purpose of receiving result. System of management should have the determined informational ties between its elements and it should have the existing feedback - otherwise, such a system would be unsustainable without feedback. Feedback allows controlling the process of management and determining the effectiveness of management influence.

In his work "General and industrial management", $\mathrm{H}$. Fayol characterized the process of management in the following way: "To manage is to foresee, organize, dispose, coordinate, and control" (Fayol, 1992). 
Thus, he determined five main functions of management. The number and content of functions of the system of management of infrastructure of support for small entrepreneurship will somewhat differ, as, according to its content, it is referred to the level of socio-economic management. General functions of management of socio-economic systems remain stable over the recent few years (Makareyko, 2009). Let's view their list with certain changes, necessary for application in the model of conception of management of infrastructure of support for SME:

- Informational provision supposes reception, collection, and storing of information, its analysis, processing of data necessary for making managerial and strategic decisions. In our opinion, the stated function should include informing the institutes of infrastructure and small entrepreneurship of the planned programs of support, of the rules of its provision, and of used instruments and order of reports;

- Forecasting - foreseeing the perspectives of development of events, phenomena, or processes, and possible state of infrastructure, as a managed object, in the future. Forecasting includes the process of modeling which supposes creation of certain model of socio-economic relations for foreseeing the decision for foreseeing the solution of managerial tasks in future. Modeling is the methods of forecasting, so we shall not distinguish it into separate function, as is done by many scientists;

- Planning - includes creation of certain quantitative and qualitative indicators of development of processes or phenomena in the system of management for specific date. As a rule, the plans are built on the basis of forecasts, contain more specific goals and tasks, and are obligatory, unlike the forecasts. This function includes the creation of programs of socio-economic development of country, regions, municipal entities, and particular spheres, as well as creation of the program of support for small entrepreneurship. In this sense, the plan and program are synonyms. Development of programs is closely connected to project activities, which is totality of measures and tasks, related to development of unique object. Thus, the function of planning, in our opinion, includes development of plans, projects, and programs of development of infrastructural support and small entrepreneurship (Ahmed et al., 2014);

- Organization - formation of system of management, setting its principles, subject list of plans' performers, and responsible for their implementation, setting the staff and resources as to performed tasks;

- Coordination - supposes coordination of joint activities of various subjects of managerial decisions in time and space for achievement of set goals and tasks of management;

- Regulation - setting obligatory requirements and procedures for objects of management, determining the order of activities, and giving orders to persons and subjects. In our opinion, the function of regulations includes two other function: management and ordering;

- Accounting - fixing the data, expressed in quantitative and qualitative indicators, on the state of the system of management for specific date and specific period;

- Control - determining correspondence or deviation of actual state of the system of management from set parameters and goals (Rossinskiy \& Starilov, 2009).

\section{Results}

\subsection{Model of Conceptual Foundation of Management of Infrastructure of Support for Small Entrepreneurship}

As a result of conducted study of conceptual foundation of the process of management, as of targeted influence of the subject of management in the object of management, the infrastructure of support for small entrepreneurship was chosen as an object of management. As the subject of management, bodies of state power and local authorities were chosen. According to the authors, conceptual foundation of management of infrastructural support for small entrepreneurship - for the purpose of realizing the sense of the infrastructure itself - should include the subject of management as influencing link, methods and forms of management, principles, functions, and object of management which in our case is variety of institutes of support for small entrepreneurship. The purpose of development of the concept of management of infrastructural support is to increase the number of small enterprises, to increase self-employment and employment, to increase the efficiency of work of small enterprises, and, accordingly, to increase its share in the gross domestic product (GDP) and gross regional product (GRP), through the complexity of provision of infrastructural services (Kiselev et al., 2015).

The infrastructure of support for SE performs the role of controlled objects in the model of management; it can be presented as a mechanism of creation of favorable conditions for effective work of SE, triggered into action by managed influence. 
The key role in creation of favorable conditions for development of SE belongs to the program of the Ministry of Economic Development and Trade - its purpose is co-financing from federal budget of regional projects for financial, property, informational, and other support for small and medium enterprises. The volume of budget financing grew over the last 10 years by 12 times, and the program was implemented in 2005 by 55 subjects of the RF, and in 2014 their number constituted 85, including Crimea (Table 1).

Table 1. Volume of budgetary provisions for implementation of financial program of support for small and medium entrepreneurship in 2005-2014

\begin{tabular}{llllllllll}
\hline & 2005 & 2006 & 2007 & 2008 & 2009 & 2010 & 2011 & 2012 & 2013 \\
\hline $\begin{array}{l}\text { Number of } 55 \\
\text { the }\end{array}$ & 64 & 6 & 67 & 82 & 82 & 80 & 82 & 83 & 85 \\
subjects of \\
the RF
\end{tabular}

Source: Ministry of Economic Development and Trade of Russia.

In 2014, according to the program of Ministry of Economic Development and Trade, the financing of the following measures was performed: provision of grants; subsidizing expenses for purchase of leasing equipment and for implementation of modernization projects, for developing of regional guarantee and micro-financing organizations, implementation of educational programs and programs of social entrepreneurship, and for creation of infrastructural objects.

However, these measures of support for SE are not enough at the modern stage. Entrepreneurs still are not satisfied with the conditions for doing business. In 2013, there was conducted the Russian initiative survey by All-Russia Public Opinion Research Center. 1,600 people were questioned in 130 communities and 42 oblasts, krais, and republics of Russia. Statistical error didn't exceed 3.4\% (Table 2).

Table 2. Conditions for development of small business in Russia

\begin{tabular}{rlllc}
\hline & & 2009 & 2013 & deviation \\
\hline 1. & Very good conditions & 3 & 2 & -1 \\
2. Rather good & 27 & 23 & -4 \\
3. Rather bad & 31 & 38 & 7 \\
4. Very bad conditions & 13 & 17 & 4 \\
5. Cannot say & 26 & 20 & -6 \\
TOTAL & 100 & 100 & - \\
\hline
\end{tabular}

Source: Entrepreneurial climate in Russia - 2013: Results of All-Russian survey

This data shows the aggravation of condition for small business in 2013, as compared to 2009. The number of respondents which evaluated the conditions positively, reduced by $5 \%$ (variants 1 and 2, and the number of negative evaluations increased by $11 \%$ (variants 3 and 4). These evaluations contradict the resonant statements 
from the Russian government as to the necessity for development of small business and alleged numerous measures and programs for its support. Statistical data shows its stagnation and are a signal for transition to completely new level of state's attitude towards small business and increase of efficiency of state policy in this sphere.

Accordingly, the further efforts of the state and municipal entities should be aimed at creation of favorable conditions for doing business, the basis of which are infrastructural objects.

Modern infrastructural objects of support for SE include:

- $\quad$ specialized state structures;

- $\quad$ public entrepreneurial unions;

- business incubators;

- industrial infrastructure;

- innovational infrastructure;

- leasing companies;

- informational agencies;

- consulting agencies;

- educational structures;

- financial and credit organizations;

- funds of support for SE;

- regional centers for coordination of support for export-oriented SE;

- social infrastructure;

- institute of ombudsman.

Studying the mechanisms of support for development of SE, it should be noted that it has 2 forms: direct support, provided for small enterprises, and indirect support, provided through institutes of infrastructure. At the modern stage of development of economy, indirect support is the most effective one.

The system of management of infrastructure of support for SE requires determination of methods of management which can be classifies according to various aspects (Vasilyeva \& Petrovskaya, 2010). There is the unambiguous division of methods of state and municipal management as to the character of influence on controlled system into direct and indirect ones - which are mostly known as administrative and economic ones (Petrov, 1972). We think that these methods are acceptable for managing the infrastructure of support for SE.

Administrative (direct) methods are characterized by direct influence on the infrastructure of support for SE and express the will of performers with the help of direct one-sided legal orders or indirect regulatory influence on the corresponding institutes of management. The methods are characterized by power motivation, compulsion, and control. The list of such methods is rather wide; it includes the following methods (Larionova, 2012):

- norming, standardization and certification, regulation, licensing, registration;

- imposition of fine and administrative arrest;

- HR, custom, trade, sanitary, ecological, and fire control;

- giving orders, conducting procedures of bankruptcy, implementing bans, etc.

Significant administrative methods of management include the methods of control which are organized in various forms, including through applying for various reports and information, front and selected checks, documentary and actual revisions. The conducted control should not be total, and controlling bodies should not violate the rights of business subjects and pursue their own interests.

Economic (indirect) methods include the methods of state management, related to the use of economic means, and financial and investment resources. By operating such economic institutes as property and entrepreneurship, state authorities can achieve a lot in implementation of set goals and functions of state management (Administrative law of the Russian Federation, 2013). Economic methods of management include: methods of financial, money \& credit, and budgetary \& tax regulation, privatization, material stimulation, support for depressive territories, subsidies and subventions, use of tax and property subsidies and material sanctions, stimulation of performers for high-quality and timely solution of set tasks, optimization of tariff rates, reduction 
of custom rates, etc. According to economists, these methods are based on two main factors - initiative and interest. The performer should receive profit, effectively performing his functions in the interest of state (Larionova, 2014). It its turn, the state should conduct financial and budget policy which stimulates the effective work of corresponding institutes, simultaneously improving the inter-budget relations, reducing the volumes of ineffective expenses, increasing state investments in perspective and vital projects, and restructuring state obligations. At the modern stage, the powerful managerial levers are the methods of state and municipal orders, flexible taxation, limitation of absolute power of natural monopolies, and export-import regulation. The use of cleverly combined methods of economic management, the need for total administrative control disappears.

Management has three forms. The proprietary research states that it is necessary to distinguish two notions: "forms of management" and "methods of management". Method of management is an important legal means which is a variety of means and methods used by state authorities and their official bodies within limits, set by the law, in order to perform management and administrative influence as to certain persons and objects. Form of management is a certain external manifestation of managerial actions (management) performed by state authorities (of federal and regional level) and by local authorities.

Forms of management are classified according to various aspects. Let us present the classification by Y.N. Starilov (Rossinskiy \& Starilov, 2009). According to him, forms of management could be divided into two large groups: legal and non-legal. Legal forms of management include legislative and law-enforcement, regulatory and law-enforcement. Legislative form of management is related to creation and development of legal norms, their discussion and confirmation. Law-enforcement form of management supposes compliance with laws and regulations for the purpose of usage of norm of law is special cases, i.e., consideration and settlement of disputes and managerial cases take place within this form. The next form of management is regulatory - it is aimed at creation of necessary conditions for public management which ensures the well-being of society and state, implementation of management functions in the sphere of state regulation, economic, administrative, political, and socio-cultural development. Law-enforcement form of management is related to performance of control managerial function.

Non-legal forms of management, or, as they are usually called, organizational forms, include (Parmenter, 2007):

1) Organizational actions or measures: meetings and conferences; distribution of positive experience and information about negative phenomena and processes in management, as well as providing practical help for local performers, development of methodological recommendations, etc.;

2) Material \& technical actions. This form of managerial activities should provide the efficiency of state and service activity, being related to records management; registration, copying and sending documents, materials, certificates, analytical calculations; material \& technical provision; information processing (Rossinskiy \& Starilov, 2009).

\subsection{Principles of Management of Infrastructural Support for Small Entrepreneurship}

The conducted research allowed concluding that management of infrastructure of support for SE should be based in the basic principles. Let us formulate the following principles, on the basis of proprietary treatment:

- targeted orientation;

- dependence on territorial development;

- systematicity;

- economic independence of process members;

- mobility and flexibility;

- balance of infrastructural provision;

- integrity and interconnection;

- complexity of provision of services;

- synergetic effect;

- openness (transparency);

- accessibility;

- competitiveness;

- membership; 
- efficiency, rationality, and principle of effective control.

The principle of sectorial orientation is the priority of goals of socio-economic development of Russia (region), coincidence of targeted landmarks of development of infrastructure with strategic goals of development of Russia and particular regions.

Principle of dependence on territorial development. Formation of goals and tasks of infrastructural support for $\mathrm{SE}$ requires preservation of interests of territories, on the basis of their geographical, demographic, economic, social, raw material, natural, and scientific potential.

Principle of systematicity. Infrastructure of support for SE should function as a single system with the following peculiar features: goals and tasks, subject and object, functions, organizational structure, integrity, independence and interconnection of system elements, of certain forms, methods, mechanisms, and instruments.

Principle of independence of business subjects. Each organization in the system of infrastructural support for SE chooses independently the type of activity, takes responsibility for expenses, and distributes profit - except for organizations which are owned by state or municipalities.

Principle of mobility and flexibility. Means the change of structure of infrastructure subjects and offered services, works, and production according to requirements of the time. It should be noted that according to structural changes of economy, there appear new elements of infrastructure which facilitate the development of nanotechnologies, social innovational infrastructure, etc.

Principle of the balance of infrastructural provision. At present, a perspective element of strategic planning and management is implementation of the principle of balance which is based on cause-consequence connections between links of controlled system and which takes into account joint influence of its parameters and factors. General meaning of the term "balance" is determined by definitions dictionaries as "correlation of mutually casual parts and elements which ensures normal functioning and work of smth". Well-balanced object is the object in harmony, balanced as to all components, accommodated, etc. (Rudenko, 2015).

Principle of integrity and interconnection. It supposes regulation of provision of infrastructural services in integrity and interconnection of federal bodies of state power, state authorities of the subjects of the Russian Federation, and local authorities. It is necessary to clearly determine the limits of authority at each level of the sphere of joint management. Local authorities should not contradict the state authority; being interconnected, they facilitate better provision of infrastructural services.

Principle of complexity means that the system of management of infrastructure should include all basic functions of management for provision of basic infrastructural support for implementation of plans and creation of favorable conditions for functioning of SE.

Principle of synergetic effect. Profit, received in the form of GDP, GRP, and budget revenues, should exceed profit received by certain object or subject of infrastructure.

Principle of openness (transparency) facilitates quick acquisition of information about existing forms of support, rules, and results of its provision.

Principle of accessibility. Infrastructural support could be granted to any small enterprises, regardless of the form of ownership, sphere of activity, or territorial belonging. Conditions of the provision of certain type of support are criteria, determined by certain project of program.

Principle of competitiveness. Development of competition between organizations of the system of infrastructural support for SE facilitates better and more effective provision of services. The state should eliminate the possibility for monopoly in provision of any infrastructural service.

Principle of membership. Institutes of infrastructure of support for SE, like small business, should take part in formation and implementation of state policy in the sphere of development of small and medium entrepreneurship, expertise of projects of regulatory acts of the Russian Federation, regulatory acts of the subjects of the Russian Federation, and legal acts of local authorities which regulate the development of small and medium entrepreneurship.

Principle of effectiveness and rationality supposes that the effect from supporting SE in the form of the growth of GDP, financial revenues, and population employment should be higher than expenses for support for SE otherwise, instruments of support are ineffective, so they should be reconsidered and corrected. 
At the modern stage, the key aspect is the support for innovational business through reduction of administrative barriers for start and development of innovational initiatives and formation of requirements of delivering the part of state orders for research \& development works to small and medium innovational business.

\section{Conclusion}

Implementation of the offered model will start the mechanism of infrastructural support for SE through managing influence of the state and municipal entities. The general result of the implementation of the concept could be the following:

- growth of the number of SE;

- creation of new jobs;

- reduction of unemployment;

- development of competition and consequent provision of better production (works and services);

- economic growth of country due to increase of GDP;

- increase of tax revenues into budget;

- growth of investment potential of small entrepreneurship;

- increase of the population life quality;

- increase of efficiency of authorities in the sphere of support for SE;

- improvement of economic situation and stabilization of social sphere.

The further development of conceptual foundations of management of infrastructural support for small entrepreneurship is seen in analysis and monitoring of services and works provided by infrastructure of support for SE, determination of the top-priority ones, evaluation of their efficiency, and detailed development of the tree of goals and perspective vector of development.

\section{References}

Ahmed, K., El Rajy, Goraya, A. R., \& Kausar, U. (2014). Mechanics of Bond Behaviour at the Joint of Normal Strength Concrete Intersecting Beam. Life Science Journal, 11(1), 41-49.

Fayol, A. (1992). General and industrial management. Management is a science and art. M.: Progress.

Forecast of socio-economic development of the Russian Federation for 2014 and planned period of 2015 and 2016. Retrieved from http://economy.gov.ru/minec/activity/sections/macro/prognoz/doc20130924_5

Kiselev, S. V., Svetovtceva, T. A., \& Rudenko, L. G. (2015). The Social Infrastructure Services in the Context of Economic Growth Factors. Mediterranean Journal of Social Sciences, 6(2), 260-267. http://dx.doi.org/10.5901/mjss.2015.v6n2s3p260

Larionova, A. A. (2012). Evaluation of efficiency of implementation of strategy of development of enterprise on the basis of the model of economic value added. Economics in industry, 3, 62-65.

Larionova, A. A. (2014). Problems of teaching of bachelors of management. Russian regions: view in future, 1 , 70-84.

Makareyko, N. V. (2009). Administrative right (p. 189). M.: Urayt. Higher education.

Miller, K., \& Bromiley, P. (2001). Strategic risk and corporate performance: An analysis of alternative risk measures. Academy of Management Journal, 3, 756-779.

Nonano, B. J. et al. (2005). Introduction to strategies and approach in universities. Publication organizational culture. New York press. Of Technological Growth, 2, 33-46.

Parmenter, D. (2007). Key Performance Indicators: Developing, Implementing and Using Winning KPI's. -New Jersey, USA: John Wiley \& Sons, Inc.

Petrov, G. I. (1972). Soviet administrative-legal relations. L.: Progress.

Popova, L. L. (Ed.). (2013). Administrative law of the Russian Federation (p. 447). Urayt Publ.

Rossinskiy, B. V., \& Starilov, Y. N. (2009). Administrative law (p. 465). M.: Norma.

Rudenko, L. G. (2015). Methodology and practice of the use of principle of balance in the formation of infrastructure of support for small entrepreneurship of the sphere of services. Transport business of Russia, 2(117), 23-26. 
Vasilyeva, L. S., \& Petrovskaya, M. V. (2010). Model of formation of reserve fund for measures of reduction of unfavorable influence on the risk of organization's activities. Bulletin of State University of Management, $10,46-60$.

\section{Copyrights}

Copyright for this article is retained by the author(s), with first publication rights granted to the journal.

This is an open-access article distributed under the terms and conditions of the Creative Commons Attribution license (http://creativecommons.org/licenses/by/3.0/). 